www.nature.com/leu

\title{
RETRACTION
}

\section{A microarray study of altered gene expression in Ara-C resistance in acute myeloid leukemia}

\author{
B Yin ${ }^{1}$, ML Tsai ${ }^{1}$, DE Hasz ${ }^{1}$, SK Rathe ${ }^{1}$, M LeBeau $^{2}$ and DA Largaespada ${ }^{1}$ \\ ${ }^{1}$ Department of Genetics, Cell Biology, and Development, The Cancer Center, University of Minnesota, Minneapolis, MN, USA \\ and ${ }^{2}$ University of Chicago, Chicago, IL, USA
}

Leukemia (2010) 24, 1543; doi:10.1038/leu.2010.59

Correspondence: DA Largaespada, Department of Genetics, Cell Biology, and Development, The Cancer Center, University of Minnesota, 6-160 Jackson Hall, 321 Church Street SE, Minneapolis, MN 55455, USA. E-mail: larga002@umn.edu

Retraction to: Leukemia 2007; 21: 1093-1097. Originally Epub 15 Feb 2007; doi:10.1038/sj.leu.2404595

Recent work has revealed that at least some of the RNA samples, cell lines or data sets used to produce gene expression microarray results in our previous letter published in Leukemia ${ }^{1}$ were likely switched. Because of the switch, we now have doubts about the list of genes initially described as differentially expressed in Ara-C-sensitive versus Ara-C-resistant cell lines (Tables 1, 2 and parts of the Discussion). We have therefore repeated the mRNA microarray analysis starting from new RNA samples and defined a different and shorter list of differentially expressed genes upon the acquisition of Ara-C resistance, which is published separately in this issue. ${ }^{2}$ The cytogenetic analysis, shRNA transduction/Ara-C sensitivity assays, and the description of highly Ara-C-resistant derivative cell lines are all fully valid as presented in the letter of 2007 . We, the authors, now wish to retract the original article published in 2007 by Yin et al. in Leukemia. ${ }^{1}$

\section{References}

1 Yin B, Tsai ML, Hasz DE, Rathe SK, Le Beau MM, Largaespada DA. A microarray study of altered gene expression after cytarabine resistance in acute myeloid leukemia. Leukemia 2007; 5: 1093-1097.

2 Rathe SK, Largaespada DA. Deoxycytidine kinase is down-regulated in Ara-C resistant acute myeloid leukemia murine cell lines. Leukemia 2010; 24: 1513-1515. 